\title{
THE GENETIC STUDIES OF FAMILIAL AMYLOID POLYNEUROPATHY IN THE ARAO DISTRICT OF JAPAN: II. STUDIES OF GENETIC MARKERS IN BLOOD
}

\author{
S. Sakoda,${ }^{1, *}$ T. Suzuki, ${ }^{1}$ S. Higa, ${ }^{1}$ M. UeJI, ${ }^{1}$ S. Kishimoto,${ }^{1}$ Y. Wada, ${ }^{2}$ \\ A. Hayashi, ${ }^{2}$ H. Matsumoto, ${ }^{3}$ T. Miyazaki, ${ }^{3}$ T. Sasazuki, ${ }^{4} \mathrm{~K}$. Nishimura, ${ }^{4}$ \\ M. Egami, ${ }^{4}$ K. OMoto, ${ }^{5}$ K. ToKunaga, ${ }^{5}$ Y. Takaba, ${ }^{6}$ and A. Nakajima ${ }^{7}$ \\ ${ }^{1}$ The Third Department of Internal Medicine, Osaka University Hospital, \\ Fukushima-ku, Osaka 553, Japan \\ ${ }^{2}$ Osaka Medical Center and Research Institute for Maternal and Child Health, \\ Izumi, Osaka 590-02, Japan \\ ${ }^{3}$ Department of Legal Medicine, Osaka Medical College, \\ Takatsuki, Osaka 569, Japan \\ ${ }^{4}$ Department of Human Genetics, Medical Research Institute, Tokyo Medical \\ and Dental University, Bunkyo-ku, Tokyo 113, Japan \\ ${ }^{5}$ Department of Anthropology, Faculty of Science, University of Tokyo, \\ Bunkyo-ku, Tokyo 113, Japan \\ ${ }^{6}$ The Arao City Hospital, Kumamoto and \\ 'The Nakajima Medical Clinic, \\ Kumamoto, 864, Japan
}

\begin{abstract}
Summary Blood samples from 21 patients with familial amyloid polyneuropathy (FAP) and 81 normal family members among 7 affected families in Arao were tested for 9 blood group systems, 8 serum polymorphic proteins, 12 red cell polymorphic enzymes, and HLA. One of the most important findings was the existence of two relatively rare variants, i.e., group specific component $\mathrm{Gc}^{*} 1 \mathrm{~A} 2$ and phosphoglucomutase PGM1*7 in 3 families. This observation suggests that the three genealogically independent families may have a common ancester. Phenotype $\mathrm{AB}$ in the $\mathrm{ABO}$ blood group system, phenotype 1 in the haptoglobin system, and $\mathrm{M}_{2}$ gene in the protease inhibitor system were not seen, and phenotype Jk(a+b-) in the Kidd groups was found in only one patient. Whether these observations reflect the characteristics of FAP in the Arao district or that of FAP itself can not be determined from the present study. No phenotype attributable to Caucasians was found, hence the study provides no support for the hypothesis that the gene for FAP was introduced into Japan by the Portuguese.
\end{abstract}

Received October 11, 1983; revised version received January 9, 1984

* To whom correspondence should be addressed. 


\section{INTRODUCTION}

Familial amyloid polyneuropathy (FAP) is a late-onset hereditary disease of unknown etiology (Glenner et al., 1978). The diagnosis of FAP is based on characteristic clinical manifestations and demonstration of amyloid deposition in peripheral nerves. The disease has a curious geographic distribution: there are large foci in Portugal (Andrade et al., 1969), Sweden (Andersson, 1976), and Japan (Araki et al., 1968; Kito et al., 1973), but the disease is uncommon elsewhere. Whether FAP in Japan has a Portuguese ancestry or not is an interesting enigma (Andrade et al., 1970). In a previous paper (Sakoda et al., 1983), we reported genealogical studies of FAP in the Arao district of Kumamoto prefecture. They revealed that there were 9 families in the focus, but did not provide any information about its origin.

The study of genetic markers seems useful for solving such clinical and genetic problems related to the disease. In this paper, we present an analysis of frequencies of thirty polymorphic genetic markers in blood from patients with FAP and their relatives in the Arao district with special reference to red cell phosphoglucomutase-1 and serum group specific component.

\section{MATERIALS AND METHODS}

Twenty-one patients with FAP (11 males and 10 females) and 81 normal family members from 7 affected families were donors of blood for examination (Table 1). The diagnosis of FAP was made on the basis of clinical and bioptic studies. Each subject was typed for 9 blood groups, 8 serum protein markers including Gm haplotypes, 12 red cell enzymes, and HLA.

Table 1. Number of patients with familial amyloid polyneuropathy in Arao tested for genetic markers and their relation to 7 families.

\begin{tabular}{llc}
\hline & \multicolumn{2}{c}{ Patients } \\
\cline { 2 - 3 } & Mamily & Female \\
\hline U & 6 & 2 \\
Sa & 3 & 1 \\
S & 1 & 2 \\
Tn & 0 & 1 \\
Tu & 0 & 2 \\
Ni & 1 & 1 \\
H & 0 & 1 \\
\hline Total & 11 & 10 \\
\hline
\end{tabular}


Blood groups (ABO, MN, P, Rh, Kell, Kidd, Duffy, Lutheran, Diego), haptoglobin (Hp), transferrin (Tf), acid phosphatase (AcP), 6-phosphogluconate dehydrogenase (6-PGD), esterase D (EsD), glutamic-pyruvic transaminase (GPT), glutamicoxaloacetic transaminase (GOT), phosphohexose isomerase ( $\mathrm{PHI}$ ), lactate dehydrogenase (LDH), adenosine deaminase (ADA), uridin-5-monophosphate kinase (UMPK), and glyoxalase 1 (Glo-1) were determined by standard methods (Giblett, 1969; Harris and Hopkinson, 1976). Group specific component (Gc) (Constans and Viau, 1977), protease inhibitor (Pi) (Kueppers and Christopherson, 1978), phosphoglucomutase-1 (PGM1) (Sutton and Burgess, 1978), and second component of complement (C2) (Tokunaga et al., 1980) were determined by isoelectric focusing. Factor B (Bf) was determined by agarose gel electrophoresis (Alper et al., 1972). Gm and $\mathrm{Km}$ were determined by hemagglutination inhibition tests (Giblett, 1969; Steinberg, 1962). Abnormal hemoglobin was determined by isoelectric focusing of globin (unpublished). 28 HLA-A, 69 HLA-B, and 12 HLA-C locus antigens were determined by lymphocyte microcytotoxity assay using the NIH standardized methods. By checking the clinical charts of Arao City Hospital, we were able to add ABO phenotypes of 19 patients, some of whom had already died, to those of the patients examined.

\section{RESULTS}

\section{Gc and $P G M l$}

Relatively rare variant alleles of Gc and PGM1 were found in 3 of 7 families affected with FAP. Gc*1A2 whose frequency is $0.6-5.1 \%$ in Japanese population (Omoto and Miyake, 1978; Matsumoto et al., 1979) was seen in the Sa (III-1 in Fig. 1), U (III-4, IV-10, IV-11, and IV-14 in Fig. 2), and Tu (II-3 in Fig. 3) families. PGM$1 * 7$ whose frequency is approximately $2.1 \%$ in the Japanese population (Satoh et al., 1977) was seen in the Sa (III-7, III-9, III-11, IV-2, IV-3, and IV-5 in Fig. 1), and U (III-4, III-13, IV-2, and IV-3 in Fig. 2) families.

\section{Other genetic markers}

There was no patient with phenotype $\mathrm{AB}$ in the $\mathrm{ABO}$ blood groups, phenotype $\mathrm{Hp} 1, \mathrm{M}_{2}$ gene in the $\mathrm{Pi}$ system, and phenotype AcPA. There was only one patient with $\mathrm{Jk}(\mathrm{a}+\mathrm{b}-)$ in the Kidd groups. In HLA, 11 of the 21 patients had the HLA Bw52 antigen; this is a relatively high proportion (0.52) for a normal Japanese population (Baur and Danilovs, 1980), and is almost the same as the figures reported by Araki et al. (1982). There was no significant difference between the FAP patient group and normal Japanese population with respect to the frequencies of other genetic markers. Phenotypes attributable to Caucasians, for example $\mathrm{K}+$ in the Kell blood groups, were not found in this study.

\section{Location of the permanent addresses of 7 afflicted families in Arao City}

From Fig. 4, it is clear that the permanent addresses of 7 afflicted families in- 

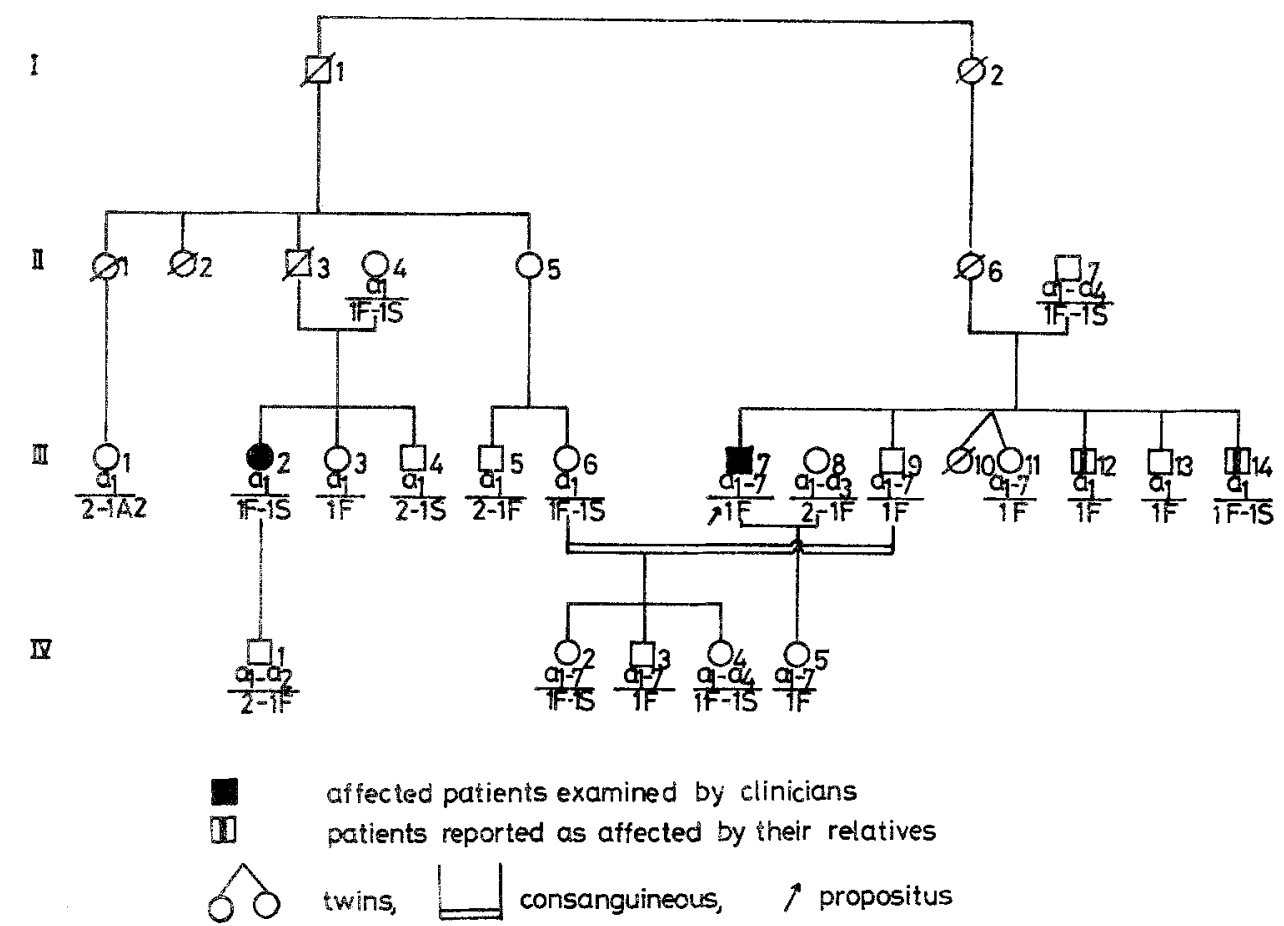

Fig. 1. The PGM1 (upper) and Gc (lower) phenotypes of the members of the Sa family.

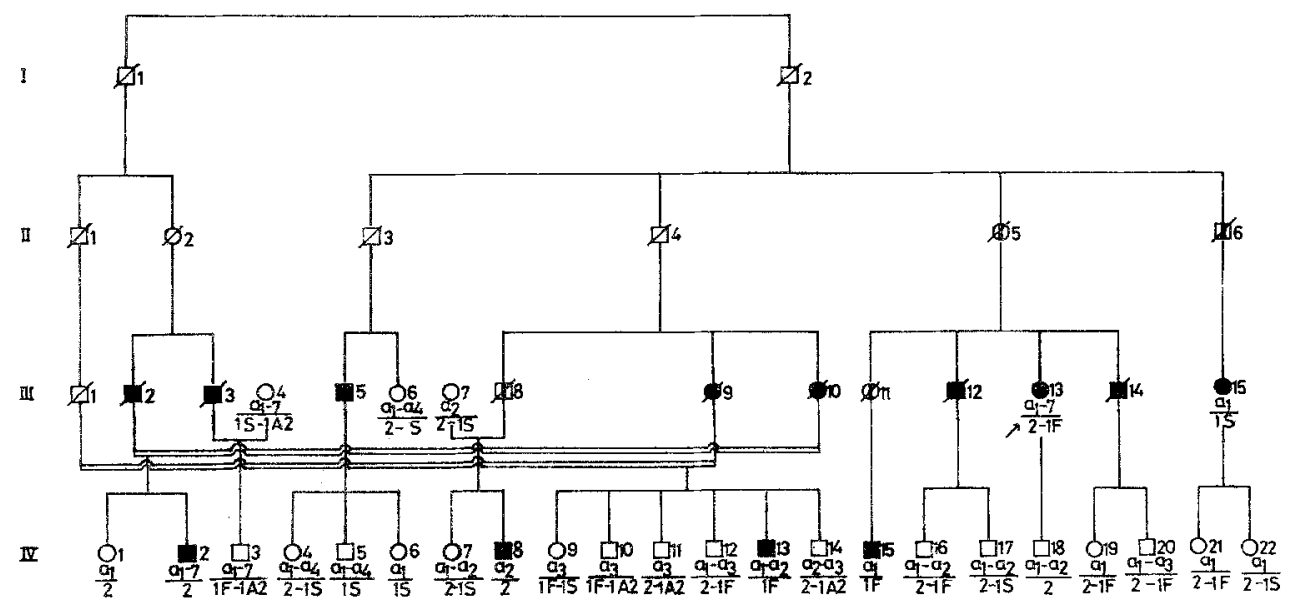

Fig. 2. The PGM1 (upper) and Gc (lower) phenotypes of the members of the $U$ family.

cluding the $\mathrm{U}, \mathrm{Tu}$, and $\mathrm{Sa}$ families in which a genetic relationship was suggested by the distribution of two variants, PGM1*7 and Gc*1A2, are located along the seashore. 


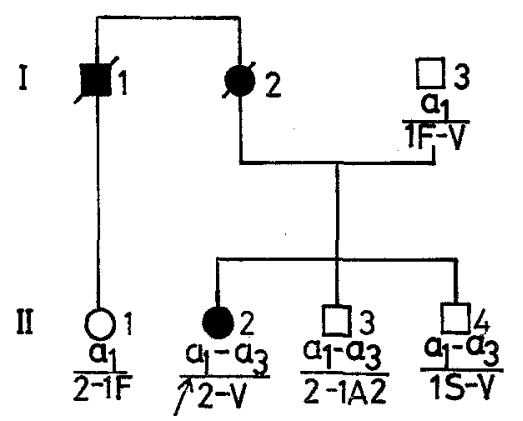

Fig. 3. The PGM1 (upper) and Gc (lower) phenotypes of the members of the Tu family. $\mathrm{GcV}$ is a variant phenotype.

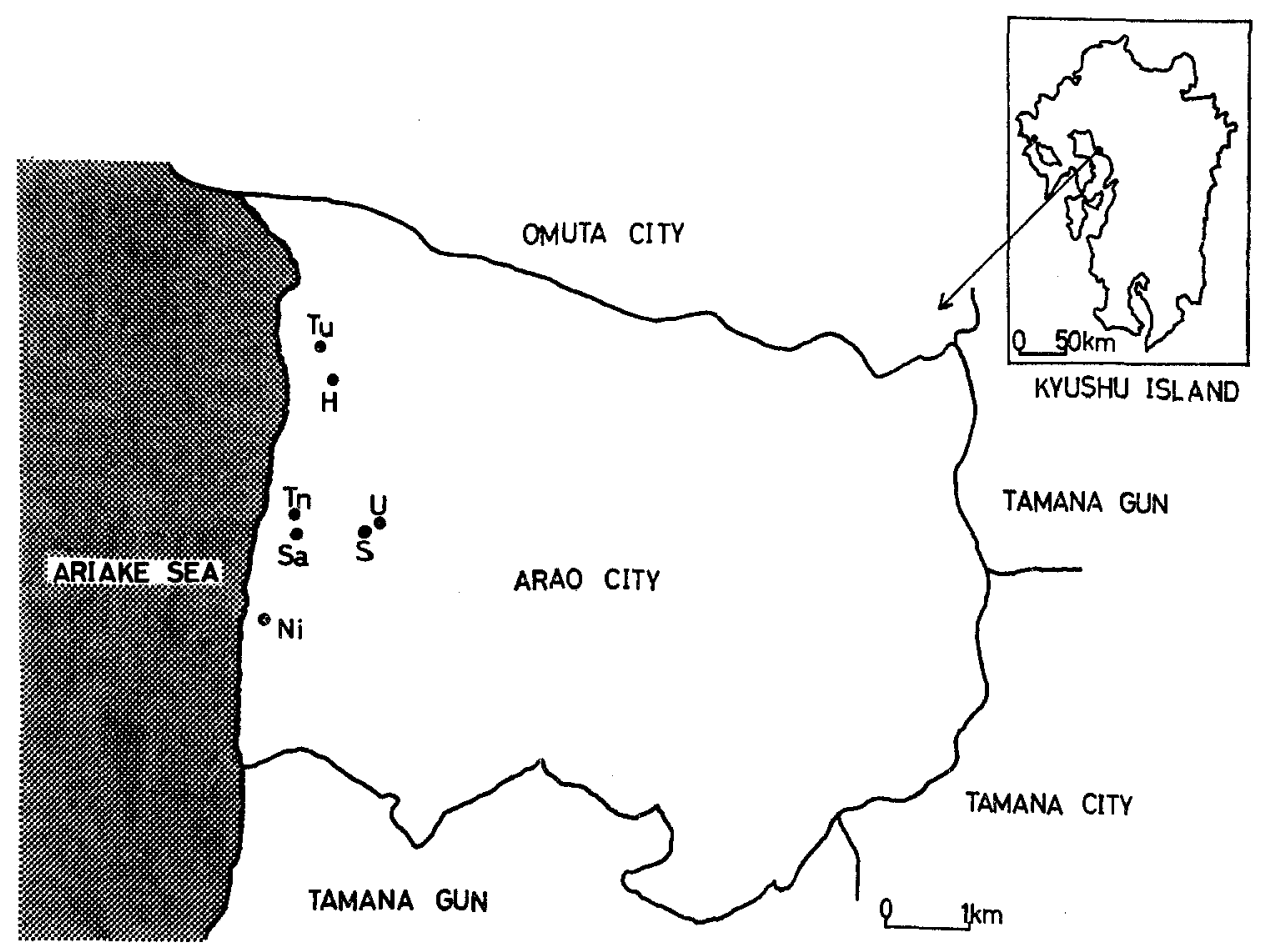

Fig. 4. The geographical distribution of the 7 afflicted families in Arao City. Gc*1A2 was found in the $U, T u$, and Sa families, and PGM1*7 was found in the $U$ and Sa families.

\section{DISCUSSION}

The present study is the first to investigate various genetic markers in patients with FAP in order to elucidate the genetic origin of seven genealogically independent 
families affected with FAP in Arao (Sakoda et al., 1983). The finding that the relatively rare variants of two genetic markers in Japan, Gc*1A2 and PGM1*7, are distributed over the three genealogically independent families suggests that the families ( $\mathrm{Sa}, \mathrm{U}$ and $\mathrm{Tu}$ ) may have a common ancester. Phenotypes attributable to Caucasians, for example $\mathrm{K}+$ in the Kell blood group, were not found in the present study and hence no evidence was found for the hypothesis that the FAP gene in Arao was derived from the Portuguese (Andrade et al., 1970). Whether a few rather unusual findings in the $\mathrm{ABO}$ blood groups, the Kidd groups, the $\mathrm{Hp}$ and the Pi systems, reflect only the characteristics of FAP in the Arao district or that of FAP itself remains to be solved. Finally, it should be stressed that the more extended studies of genetic markers are promising in elucidating the genetic characteristics of the focus and further solving the origin of the mutant gene in Arao.

Acknowledgments We are indebted to Dr. T. Tsuru, Mitsui Tenryo Hospital, Dr. K. Shida, Omuta Rosai Hospital and Mr. H. Kido, an epidemiologist in Arao for their cooperation. Thanks are due to Prof. J. Miller, University of British Columbia, for looking over the manuscript. This work was supported by grants for Specific Diseases and for Monitoring Study of Congenital Disorders from the Ministry of Health and Welfare.

\section{REFERENCES}

Alper, C.A., Boenish, T., and Watson, L. 1972. Genetic polymorphism in human glycine-rich betaglycoprotein. J. Exp. Med. 35: 68-80.

Andersson, R. 1976. Familial amyloidosis with polyneuropathy. Acta Med. Scand. Suppl. 590: $1-64$.

Andrade, C., Canijo, M., Klein, D., and Kaelin, A. 1969. The genetic aspect of the familial amyloidotic polyneuropathy. Humangenetik 7: 163-175.

Andrade, C., Araki, S., Block, W.D., Cohen, A.S., Jackson, C.E., Kuroiwa, Y., McKusick, V.A., Nissim, J., Sohar, E., and Van Allen, M.W. 1970. Hereditary amyloidosis. Arthr. Rheum. 13: 902-915.

Araki, S., Mawatari, S., Ohta, M., Nakajima, A., and Kuroiwa, Y. 1968. Polyneuritic amyloidosis in a Japanese family. Arch. Neurol. 18: 593-602.

Araki, S., Kurihara, T., and Kuribayashi, T. 1982. Familial amyloidotic polyneuropathy and HLA. Clin. Immunol. 14 [Suppl. 4]: 96-102 (in Japanese).

Baur, M.P. and Danilovs, J.A. 1980. Population analysis of HLA A, B, C, DR, and other genetic markers. In Histocompatibility Testing, Terasaki, Paul I., ed., UCLA Tissue Typing Laboratory, Los Angeles, pp. 955-993.

Constans, J. and Viau, M. 1977. Group specific component: Evidence for two subtypes of the $\mathrm{Gc}^{1}$ gene. Science 198: 1070-1071.

Giblett, E.R. 1969. Genetic Markers in Human Blood, F.A. Davis Co., Phila., Pa.

Glenner, G.G., Ignaczak, T.F., and Page, D.L. 1978. The inherited systemic amyloidosis and localized amyloid deposits. In The Metabolic Basis of Inherited Disease, Stanbury, J.B., Wyngaarden, J.B., and Fredrickson, D.S., eds., 4th Ed., McGraw-Hill Book Co., New York, pp. 1308-1339.

Harris, H. and Hopkinson, D.A. 1976. Handbook of Enzyme Electrophoresis in Human Genetics, North-Holland/American Elsevier, Amsterdam, Oxford, New York.

Kito, S., Fujimori, N., Yamamoto, M., Itoga, E., Toyoizumi, Y., Kakizaki, T., Mitsui, Z., Ichikawa, H., Morinaga, T., Wakatsuki, K., Satoh, S., and Iwasaki, I. 1973. A focus of familial amyloid polyneuropathy. Nippon Rinsho 31 : 2326-2338. 
Kueppers, F. and Christopherson, M.J. 1978. Alpha ${ }_{1}$-antitrypsin: further genetic heterogeneity revealed by isoelectric focusing. Am. J. Hum. Genet. 30: 359-365.

Matsumoto, H., Toyomasu, T., Tamaki, Y., Katayama, K., and Matsui, K. 1979. The distribution of $\mathrm{Gc}$ subtypes in Japanese and its application in paternity case. Jpn. J. Legal Med. 33: 74-79.

Omoto, K. and Miyake, K. 1978. The distribution of the group specific component (Gc) subtypes in Japanese. Jpn. J. Human Genet. 23: 119-135.

Sakod̉a, S., Suzuki, T., Higa, S., Ueji, M., Kishimoto, S., Hayashi, A., Yasuda, N., Takaba, Y., and Nakajima, A. 1983. Genetic studies of familial amyloid polyneuropathy in the Arao district of Japan: I. The genealogical survey. Clin. Genet. 24: 334-338.

Satoh, C., Ferrell, R.E., Tanis, R.J., Ueda, N., Kishimoto, S., Neel, J.V., Hamilton, H.B., and Baba, K. 1977. The frequency in Japanese of genetic variants of 22 proteins. Ann. Hum. Genet. (Lond.) 41: 169-183.

Steinberg, A.G. 1962. Progress in the study of genetically determined human gamma globulin types (the Gm and Inv groups). Progress Med. Genet. 2: 1-33.

Sutton, J.G. and Burgess, R. 1978. Genetic evidence for four common alleles at the phosphoglucomutase-1 locus detectable by isoelectric focusing. Vox Sang. 34: 97-103.

Tokunaga, K., Omoto, K., Araki, C., and Juji, T. 1980. Genetic polymorphism of the second component of human complement (C2) in Japanese. Jpn. J. Human Genet. 25: 287-293. 